Acta Universitatis Sapientiae, Philologica, 8, 3 (2016) 85-101

DOI: 10.1515/ausp-2016-0033

\title{
About the Definition, Classification, and Translation Strategies of Idioms
}

\author{
Gabriella KOVÁCS \\ Sapientia Hungarian University of Transylvania \\ Faculty of Technical and Human Sciences, Târgu-Mureş \\ Department of Applied Linguistics \\ kovagabi@yahoo.com
}

\begin{abstract}
In translator training, the process of planning and implementing the teaching process and the design of teaching materials should be dynamic and flexible. With the future purpose to design teaching materials for idiom translation, this study proposes to explore those characteristics of idioms which might cause difficulties when translating them and some of the various classifications of idioms. Some of the relevant factors which might determine the appropriateness and acceptability of idiom translation and some of the translation strategies recommended in the specialized literature will also be presented. We proposed to analyse the idiom-translating solutions and strategies which the literary translator of the novel "A Game of Thrones" chose while translating it into Hungarian. Our aim is to decide whether the novel can be an appropriate source for authentic teaching material. We chose this novel mainly because it has recently become very popular among students, it is rich in idioms, and we believe that different aspects of idiom typology and different strategies used in idiom translation can be exemplified, demonstrated, and practised with the help of different tasks based on the original text and its Hungarian translation.
\end{abstract}

Keywords: translation of idioms, translator trainees, translation strategies, teaching material, task design

\section{Introduction}

Translator-training curriculums may vary and have different priorities based on market demands, the various needs of the trainees, and the languages involved. The process of planning and implementing the teaching process and the design of teaching materials should remain dynamic, always flexible enough to be changed and adapted to the latest demands of the market and the students. Translatortraining programmes involve a multidisciplinary approach, concentrating not 
only on the proficient knowledge and use of the source and the target language but also on culture-specific aspects, the main features of different text types and genres, and the skills to search and use any available sources in order to produce appropriate and acceptable translations. Experience is a determining factor in this domain and it can be gained only by constant practice.

Translating idioms has always been considered a challenging decision-making process for translators, which requires a lot of experience and creativity. Even acknowledged and experienced translators, who ideally have a well-founded knowledge of the target language and its cultural aspects, cannot match the ability of native speakers in deciding when - meaning in what text type or context certain idioms would or would not be appropriate. A thorough knowledge of the source and target language is indispensable in this process, which also requires creativity and the skill, willingness, and perseverance to search for the best equivalent. Along their studies and the subsequent years of experience, translators usually develop - consciously or instinctively - different strategies and solutions regarding the translation of idioms.

Another important factor contributing to efficient translations is that translators should ideally translate into their native language and not into a second language. It is well known that they possess a more profound knowledge of the linguistic and cultural aspects of their mother tongue than of a second language studied at school or university. Hervey and Higgins point out that translator trainings usually focus on translations into the native language because this way higherquality works can be achieved as compared to translating into a second language (Hervey \& Higgins 2002). Baker also believes that translators should try to work mostly into their native language, one of her supporting arguments being that foreign language speakers' competence in using idioms almost never equals that of native speakers' (Baker 1992). Therefore, those who translate into a foreign language can never achieve the sensitivity of a native speaker in judging how and when an idiom should be used. Reiss highlights that translators should make it possible for the target-language readers to understand and see the text in the terms of their own cultural context. However, because of the increasing market demands for translations, translators often have to translate into a second language. In these circumstances, it becomes even more imperative to concentrate on culture-specific elements in translator training and the different strategies that can be applied in dealing with their translation (Reiss 2014).

This study aims to discuss some of the relevant factors which might determine the appropriateness and acceptability of the translation of idioms and to present some of the strategies and frequently used techniques recommended in the specialized literature. We also proposed to explore the various solutions and strategies which the translator of the novel "A Game of Thrones" chose while translating certain idioms into Hungarian. The aim of this analysis is to use the 
novel as a source for authentic teaching material regarding the translation of idioms in translator training. We chose this novel mainly because it has recently become very popular among students and we believe that different aspects and difficulties of idiom translation can be demonstrated and practised with the help of different tasks based on the original text and its Hungarian translation.

\section{Definition of idioms}

Before exploring the possible strategies regarding the translation of idioms, it is necessary to describe some of those features which can be responsible for the difficulties in their translation. The first problem would be related to their definition, which, as Cacciari states, is a difficult and controversial task, along with the description of their acquirement and understanding (Cacciari 1993). She mentions several factors which are responsible for these difficulties as, for instance, the fact that idiomatization is a process, meaning that structures acquire their idiomaticity gradually; or the fact that they are analysable and holistic at the same time, meaning that they are built of more constituent words, but their global meaning cannot be reduced to the meaning of these words; and the fact that there are different types of idioms, some of them retaining the original meaning of their constituent words, others having a completely different meaning.

However, in Longman dictionary of language teaching and applied linguistics, the term idiom is defined simply as "an expression which functions as a single unit and whose meaning cannot be worked out from its separate parts. For example: She washed her hands of the matter means She refused to have anything more to do with the matter" (Richards \& Schmidt 2010: 270). A similar definition is given by Seidl and McMordie, who say that "an idiom can be defined as a number of words which, when taken together, have a different meaning from the individual meanings of each word" (Seidl \& McMordie 1988: 12-13). Brenner believes that native English speakers simply use idioms without being aware what constitutes them. He points out that in dictionaries certain confusion and disagreement can be observed regarding the definition of idioms. However, the most common one is "two or more words together that, as a unit, have a special meaning that is different from the literal meaning of the words separately" (Brenner 2003: 4-5). These units sometimes are not only different in meaning from what the words would mean separately but they are also considered more effective or gripping in certain contexts.

Baker considers it important to distinguish idioms from collocations. She does this based on the transparency of meaning and flexibility of patterning. According to her, while collocations allow variations in form and are more flexible patterns of language (e.g. deliver a letter, a letter has been delivered, 
delivery of a letter), idioms are "frozen patterns of language which allow little or no variation in form and often carry meanings which cannot be deduced from their individual components". She also adds that there are certain things which under normal circumstances (except jokes or play on words) cannot be done to an idiom: changes in word order, deletion of words from it, adding other words to it, replacement of a word with another, or changes in its grammatical structure (Baker 1992: 63).

\section{Classification of idioms}

McPherron and Randolph states that the majority of linguists, writers, poets, language teachers, and language learners admit that idioms may help to give vivid descriptions and that they prove to be more effective and powerful than literal, non-idiomatic language. However, they also agree with the fact that idioms cannot be easily classified and they are definitely a challenge for language teachers (McPherron \& Randolph 2014).

The difficulties related to their classification are pointed out also by Kövecses, who compares the linguistic expressions called idioms to a "mixed bag" which "involves metaphors (e.g. spill the beans), metonymies (e.g. throw up one's hands), pairs of words (e.g. cats and dogs), idioms with it (e.g. live it up), similes (e.g. as easy as pie), sayings (e.g. a bird in the hand is worth two in the bush), phrasal verbs (e.g. come up, as in "Christmas is coming up"), grammatical idioms (e.g. let alone), and others” (Kövecses, 2010: 231). Consequently, classification is an important issue regarding idioms. If there are different types of idioms, there might be differences regarding the ways they are understood, learned, and translated. There have been several attempts to categorize them.

According to Fernando, there are three sub-classes of idioms. Pure idioms are conventionalized, non-literal multiword expressions. They are always nonliteral; they may be either invariable or may have little variation. In addition, these idioms are considered to be opaque (e.g. to spill the beans has nothing to do with the beans). Semi-idioms can have one or more literal constituents and one with non-literal sub-sense. Therefore, this type of idiom is considered partially opaque (e.g. foot the bill, which means 'pay'). Literal idioms are either invariable or allow little variation. They are considered to be transparent because they can be interpreted based on their parts (e.g. of course, in any case, for certain) (Fernando qtd in Strakšiene 2009: 14).

Seidl and McMordie point out that idioms can have different (regular, irregular, or even grammatically incorrect) structures and different forms. However, the structure does not determine the clarity of meaning. The three main types according to them are: idioms with irregular form and clear meaning (e.g. give 
someone to understand, do the dirty on someone); idioms with regular form, but unclear meaning (e.g. cut no ice, bring the house down); and idioms with irregular form and unclear meaning (e.g. be at large, be at daggers drawn). They concluded that most idioms belong to the second group, but even within this group there might be differences regarding the clarity of the idioms (Seidl \& McMordie 1988: 13).

Cacciari and Glucksberg proposed a functional approach based on their degree of compositionality and their semantic transparency. According to the dimension of compositionality, idioms can be non-compositional, partially compositional, and fully compositional (Cacciari \& Glucksberg, 1991).

In noncompositional idioms, no relations between the idiom's constituents and the idiom's meaning can be discerned, as in the idiom cheescake to refer to pinup art [...]. In partially compositional idioms, some relationships between an idiom's constituents and its idiomatic meaning can be discerned and exploited. Although one could not infer the meaning to die from the literal meaning of kick the bucket, the idiom's literal meaning does constrain its use and comprehension. [...] In fully compositional idioms, the constituents map directly onto their idiomatic referents, as in the idiom pop the question" (Glucksberg 2001: 73).

Some linguistic studies attempted to decide whether compositional idioms or non-compositional idioms are easier to understand. For compositional idioms, the result of linguistic analysis corresponds with the idiomatic meaning, and therefore their comprehension is facilitated. In the case of non-compositional idioms, the linguistic and idiomatic meanings do not correspond, hence their comprehension becomes more difficult. That is why compositional idioms are understood more easily than non-compositional ones (ibid. 74).

According to Glucksberg, another possibility to classify idioms is based on their degree of transparency, the extent to which the meaning of an idiom can be deduced from the meanings of its constituents. He distinguishes opaque and transparent compositional idioms.

In compositional-opaque idioms, the relations between an idiom's constituents and its meaning may be opaque, but the meanings of individual words can nevertheless constrain both interpretation and use. For the idiom kick the bucket, the semantics of the verb to kick can constrain interpretation. Kicking is a discrete act, and so one could not say he kicked the bucket all week, even though one could say he lay dying all week" (Glucksberg 2001: 74). 
In the case of compositional-transparent idioms, "there are one-to-one semantic relations between the idiom's constituents and components of the idiom's meaning. In the idiom break the ice, for example, the word break corresponds to the idiomatic sense of abruptly changing an uncomfortable social situation, and the word ice corresponds to the idiomatic sense of social or interpersonal tension" (ibid. 74). Besides non-compositional, compositional-opaque, and compositional-transparent idioms, there is also the quasi-metaphorical type. Such idioms, according to Glucksberg, convey meaning through their allusional content, calling in one's mind prototypes or stereotypes referring to certain situations, actions, or people: "they can simultaneously refer to an ideal exemplar of a concept and characterize some event or situation as an instance of that concept. For the concept doing something prematurely, for example, one might use the metaphorical idiom crossing one's bridges before coming to them" (ibid. 75). According to Cacciari and Tabossi, these quasi-metaphorical idioms are based on similar communication strategy as metaphors in contexts such as "my lawyer is a shark" or "my job was a jail" (Cacciari and Tabossi 1993). Here shark refers to merciless, ruthless people, while jail alludes to unpleasant circumstances. Quasi-metaphorical idioms work in a similar way.

According to the degree of opacity of idioms, Kvetko recommends another typology. In his classification, there are pure or demotivated idioms, so-called phraseological fusions, where there is no connection between the meaning of individual constituents and the meaning of the whole idiom, for instance: red tape, kick the bucket, hair of the dog that bit you, white elephant. Semi-opaque or partially motivated idioms are figurative idioms, phraseological unities with a certain connection between the meaning of individual words and the meaning as a whole, such as in add fuel to the flames, put one's card on the table, have a free hand. Semi-transparent or semi-idioms are phraseological combinations, where one of the constituents is used in figurative, idiomatically bound meaning, while the other has a literal, direct meaning: promise somebody the moon, foot the bill, lie through one's teeth (Kvetko 2009: 106-107).

Recognizing, understanding, learning, and, above all, translating idioms can also be influenced by the different variants and new formats they might appear in. Glucksberg draws the attention to the fact that there can be a difference between learning and understanding an idiom such as spill the beans and recognizing it as a variant like he didn't spill a single bean (Glucksberg 2001). A variant's meaning is not stored and directly available in one's memory, wherefore recognizing variants involves complex mental processing and the implementation of different strategies.

In the same line of ideas, Kvetko proposes a classification of idioms from a semantic point of view, based on their fixedness or stability. He claims that there are unchangeable idioms, which are completely fixed and cannot undergo any 
modifications (e.g. once in a blue moon, red tape), and there are changeable idioms allowing certain variations. Among changeable idioms, he distinguishes the following possibilities for variation:

(1) grammatical variations involve limited, irregular syntactical or morphological changes such as tense, word order, form, articles, and their results are grammatical variants (e.g. have been in the wars - had been in the war; on and off - off and on; turn up one's nose - turn one's nose up);

(2) lexical variations refer to optional or obligatory variations regarding the lexical structure of idioms, and their results are lexical variants (e.g. out of a clear sky - out of a clear blue sky; last straw - final straw). In certain cases, changeable idioms can undergo both grammatical and lexical changes (e.g. a/the skeleton in the cupboard - a/the family skeleton; there is no smoke without fire, where there is smoke, there's fire);

(3) orthographic variations refer to changes in spelling, using different punctuation marks, or using small or capital letters; the results of these changes are orthographic (spelling) variants (e.g. nosy parker, nosy Parker, pay lip service, pay lip-service);

(4) geographic variations are preferred only in certain parts of the Englishspeaking world and they can include any of the previously mentioned variations; examples for geographical variants: on second thoughts (British English) - on second thought (American English); a skeleton in the closet (American English) a skeleton in the cupboard (British English) (Kvetko 2009: 104-105).

Kvetko also proposes a classification of idioms based on their construction. From this point of view, there can be verbal, verbless, sentence, and minimal idioms. Verbal idioms have verbal syntagmatic structures, they often consist of a verb and an object (e.g. make up one's mind, open somebody's eyes, sleep like a $\log$ ). Verbless idioms have a syntagmatic structure without a verb. A non-verbal idiom can be nominal, adjectival, or adverbial (e.g. black sheep, a square peg in a round hole, (as) fit as a fiddle, once in a blue moon). Sentence idioms have the complex structure of a sentence (e.g. the coast is clear, talk of the devil and he'll soon appear, make hay while the sun shines). According to some linguists, there is also a category of minimal idioms, which refer to idiomatic expressions consisting of at least one word (e.g. by heart, like hell) (ibid. 106).

Subsequently, it can be seen that there have been several attempts to classify idioms. We believe that a certain awareness of the existence of different types of idioms can be of great help in the process of their recognition, understanding, and ultimately their translation; therefore, we believe that it is important to include both theory and practice regarding idiom typology in translator-training programmes. 


\section{Some challenging factors in recognizing, understanding, and translating idioms}

The ambiguities regarding the definition of idioms, their characteristics, and the attempts at their classification shortly discussed above may in themselves give an explanation for the difficulties translators have to face while translating them. However, there are some other factors which can contribute to the extent of the challenge.

English language is considered to be a language rich in idioms; therefore, translators should be aware of their usage, types, and characteristics. The large number of idioms in English and the fact that even native speakers might have difficulties in understanding them (speaking different varieties of the language, i.e. British, American, Australian, Canadian, or other varieties) may be considered a source of problems in their translation as well.

There can be found dictionaries of idioms belonging to the different varieties of English, for example Webster's new world American idioms handbook by Gail Brenner or English idioms dictionary by Ralph Pilkington. Obviously, most of these dictionaries contain idioms used in all English-speaking countries besides the ones belonging to the variety of English they claim to represent. Brenner himself admits this - if we read between the lines - when he states that "there are over 10,000 idioms in American English, and some of them have been in use for more than 2000 years" (Brenner 2003: 3). According to Bárdos, 3,000-4,000 words constitute the active vocabulary and 4,000-5,000 words the passive vocabulary of an advanced learner (Bárdos 2000). The approximate number of idioms in English compared to the number of words in the active and passive vocabulary of an advanced learner might help us understand the extent of the challenge a translator trainee faces when translating idioms if we consider that his/her command of the second language ideally corresponds to that of an advanced learner's but not to that of a native speaker's.

According to Irujo, some of the explanations for the problems that non-native speakers of English encounter regarding idioms are the following: non-literalness, exposure to idioms, and correct use. By non-literalness she means that "they do not mean what they say. [...] For example, the idiomatic meaning of he spilled the beans has nothing to do with beans or with spilling in its literal sense. Most idioms also have literal counterparts, which makes them even harder to learn" (Irujo 1986: 236). In the case of translators, non-literalness and possible literal counterparts might create difficulties in recognizing or properly translating an idiom. Regarding the exposure to idioms, the problem is in fact non-exposure or not enough exposure because native speakers tend to use simplified language when speaking to second-language learners or non-native speakers. "Thus, 
learner's exposure to idioms appears mainly in non-interactive situations, where there is no opportunity for negotiation of meaning, rather than in interactive situations which allow learners to clarify meaning and receive feedback on use" (ibid. 237). Translator trainees are in fact language learners themselves - ideally advanced learners, but that is not always the case -; therefore, their training should include the development of the necessary skills to recognize idioms and clarify their meaning. By correct use, Irujo draws the attention to the following factors: "idioms vary in formality from slang (you got it) and colloquialisms (he kicked the bucket) to those which can be used in formal situations (run the risk)" and the fact that "many idioms have grammatical constraints" (ibid. 237). Therefore, it is not enough for a translator to know or recognize an idiom; he/ she must also be capable of deciding whether it is acceptable or not to use it in a certain text, depending on its register or genre.

Baker claims that "the main problems that idiomatic and fixed expressions pose in translation relate to two main areas: the ability to recognize and interpret an idiom correctly and the difficulties in rendering various aspects of meaning that an idiom or a fixed expression conveys into the target language" (Baker 1992, 65). She specifies four main difficulties in translating idioms. The first is the lack of an equivalent of an idiom or a fixed expression in the target language. The same meaning can be expressed with a single word in one language and with the help of a fixed expression in another. Therefore, the expectation to find equivalent idioms easily in the target language is unrealistic. Or, some idioms might be culturespecific. In this case, "it is not the specific items an expression contains but rather the meaning it conveys and its association with culture-specific contexts which can make it untranslatable or difficult to translate" (ibid. 68). However, as Klaudy emphasizes, translators should be not only linguistic but also cultural mediators and it should be part of their professional competence to know the two cultures and be able to "compare and assess the geographical, historical, social and cultural aspects of two language communities", and develop "strategies to bridge the gaps between different cultures" (Klaudy 2003: 175). The second difficulty enlisted by Baker appears when an idiom has a similar counterpart in the target language, but it is used in different contexts or situations because of its different connotations. The third type of problem occurs when "an idiom may be used in the source text in both its literal and idiomatic senses at the same time. Unless the target-language idiom corresponds to the source-language idiom both in form and in meaning, the play on idiom cannot be successfully reproduced in the target text" (Baker 1992: 69). The fourth difficulty mentioned by Baker is related to the different source-language and target-language conventions regarding the use of idioms in written discourse, certain contexts, or the frequency of their use.

Some of the problems regarding the translation of idioms and fixed expressions are also mentioned by Davies, and they show close similarity with the ones defined 
by Baker: recognition; no equivalent in the target language; a similar counterpart in the target language with a different context of use; an idiom used in the source text both in its literal and idiomatic sense at the same time; difference between the convention, context, and frequency of use in the source and target languages (Davies 2004: 193).

The above mentioned problems and difficulties may all be faced by translators in their struggle to achieve naturalness. In Newmark's definition, the level of naturalness achieved in a translation may depend on whether it makes sense, reads naturally, and "is written in ordinary language, the common grammar, idioms and words that meet that kind of situation" (Newmark 1988: 24). Naturalness is important in all text types; this is the main reason why it is almost impossible to produce a proper translation if the translator is not working into his/her language of habitual usage. In order to achieve naturalness, translators should be able to detach themselves mentally from the source-language text and reread and check their work regarding the following: Would they ever see such language usage in texts belonging to the same genre and register written originally in the target language? Is that usage a common usage in that type of writing? Is it frequenly used? Newmark also admits that naturalness can be defined easily, "but not so easy to be concrete about. Natural usage comprises a variety of idioms or styles or registers determined primarily by the 'setting' of the text, i.e. where it is typically published or found, secondarily by the author, topic and readership, all of whom are usually dependent on the setting" (ibid. 26). When translating idioms, naturalness might also be compromised by the use of books of idioms, dictionaries, which often fail to distinguish "between what is current (e.g 'keep my head above water') and what is dead (e.g. 'dead as a door nail')", and by the difficulty of matching the equivalence of meaning with the equivalence of frequency (ibid. 28).

Based on all these challenging factors in recognizing, understanding, and translating idioms, it can be concluded that idioms are definitely a noteworthy domain for translator trainees. When dealing with these difficulties, translators may use various strategies.

\section{Strategies used in the translation of idioms}

In order to translate idioms from the source language into the target language, the translator has to choose the most appropriate strategy, taking into consideration the peculiarities, function, culture-specificity, semantic and structural unpredictability of these expressions.

In Baker's opinion, the most fortunate and ideal situation would be that they find an idiom with a similar meaning in the target language. However, if they do not, then there are other factors to consider: 
For example, the significance of the specific lexical items which constitute the idiom, i.e. whether they are manipulated elsewhere in the source text, as well as the appropriateness or inappropriateness of using idiomatic language in a given register in the target language. The acceptability or nonacceptability of using any of the strategies described below will therefore depend on the context in which a given idiom is translated. [...] Questions of style, register, and rhetorical effect must also be taken into consideration (Baker 1992: 72).

She proposes five strategies. Some of them will be exemplified here with English-Hungarian translations.

1) Using an idiom of similar meaning and form

This strategy might seem to be the ideal solution, but other aspects, such as register, style, or rhetorical effect, must be considered as well. Baker agrees with Fernando and Flavell in their warning against the urge that most translators feel to search for an idiom in the target language risking to use even inappropriate ones (Fernando \& Flavell qtd in Baker 1992).

Using an idiom of similar meaning and form means to use an idiom in the target language which has approximately the same meaning as the sourcelanguage idiom and it contains equivalent lexical items (e.g. break someone's heart - összetörni valakinek a szívét, face to face - szemtól szembe, step by step - lépésról lépésre). However, such ideal matches can rarely be achieved.

2) Using an idiom of similar meaning but dissimilar form

This strategy is based on the possibility to find an idiom in the target language with a similar meaning to that of the source idiom or expression, but containing different lexical items (e.g. Jack-of-all-trades - ezermester, one good turn deserves another - jótett helyébe jót várj).

3) Translation by paraphrase

According to Baker, this can be considered the most common way of translating idioms when it is inappropriate to use idiomatic expressions in the target text because of differences in stylistic preferences or when no match can be found in the target language. (E.g. "One frequent criticism of the Manitoba Government throughout the language controversy was that it never seemed to get a handle on the issue." - A nyelvi vita idején egyik gyakori bírálat Manitoba kormányával szemben az volt, hogy a jelek szerint soha nem volt képes kezelni/uralni a helyzetet.)

4) Translation by omission

In certain situations, idioms may be omitted from the target text. The reason for this may be that they cannot be easily paraphrased, they do not have a close match in the target language, or because of stylistic considerations. 
5) Strategy of compensation

This is a strategy which Baker does not try to illustrate because it would take up too much space. "Briefly this means that one may either omit or play down a feature such as idiomaticity at the point where it occurs in the source text and introduce it elsewhere in the target text" (ibid. 78).

Baker concludes that the use of the typical phraseology of the target language, including its own natural fixed and semi-fixed expressions, the right level of idiomaticity can seriously influence the readability of a translation. If a translator manages to deal with these issues successfully, it means that his or her target text will feel less ‘foreign' (Baker 1992).

\section{Idiom translation strategies in the Hungarian translation of the novel "A Game of Thrones"}

In this part of the study, the analysis of some idiom-translating solutions and strategies are presented, which the literary translator of the novel "A Game of Thrones" chose while translating it into Hungarian. The aim of the analysis was to decide whether the target text and its Hungarian translation were eligible for being used as sources for teaching materials. This novel was chosen mainly because it is relatively rich in idioms and it has recently become very popular among students. It was translated into Hungarian by Tamás Pétersz, an experienced literary translator, with the title Trónok Harca.

The translations of the following thirty idioms were analysed (extracted from the first eighty pages of the novel): did not rise to the bait; drag him into the quarrel; being made light of; his bowels had turned to water; made his hackles rise; had caught him red-handed; brought up the rear; in the dead of night; an old hand in justice; picked their way carefully; (heard) the breath go out of him; tore his eyes away; to face his fears; gave her a chill; guard your tongue; were talking a toll (on the king); drained a glass; sated his curiosity; a man half in his cups; (Jon) swelled with pride; I never asked for this cup to pass to me; on wary feet; in a fit of guilt; (Robert) can barely stomach his brothers; (Why else would he) leave the seat of his power; looked very much the part; (Jaime and Tyrion) were somewhat less peas in a pod; nurse his resentment; her stomach was a roil; in the blink of an eye. They were extracted from the text in the order as they occurred. They are of different types and some of them can be regarded as variants of certain idioms.

First, the types of the expressions from the target text were identified from a semantic point of view, based on a simplified classification deduced from the typology proposed in the specialized literature: 
(1) transparent idioms - there are obvious semantic relations between the meaning of the idiom's constituents and the idiom's meaning;

(2) semi-transparent idioms - there are some semantic relations between the meaning of certain constituents and the idiom's meaning;

(3) opaque idioms - there is no semantic relation between the meaning of the idiom's constituents and the idiom's meaning.

They were also categorized based on their fixedness following Kvetko's (2009) typology: (1) unchangeable idioms (completely fixed and cannot undergo any modifications) and (2) changeable idioms. In the case of changeable idioms, grammatical, lexical, and orthographical changes were examined.

The idioms were also analysed regarding their construction. Using Kvetko's (2009) classification, we tried to identify verbal, verbless, sentence, and minimal idioms.

Regarding the applied strategies, the translator's choices were categorized based on Baker's strategies. Three of them could be identified:

(1) using an idiom of approximately similar meaning and form;

(2) using an idiom of similar meaning but dissimilar form;

(3) translation by paraphrase.

As part of the analysis, we also explored what other translation possibilities would be acceptable within the given context besides the option of the literary translator.

The following five examples illustrate the methodology of our analysis:

1. Source text: "Gared did not rise to the bait. He was an old man, past fifty, and he had seen the lordlings come and go" (Martin 2011). The meanings of the idiom to rise to the bait given in The Free Dictionary - Idioms are the following: to respond to an allurement; to fall for an enticement or fall into a trap. The idiom to rise to the bait can be considered an opaque idiom because there is no semantic relation between the meaning of its constituents and the meaning of the expression as a whole. Regarding its fixedness, it is changeable from grammatical point of view as the tense of the verb can be altered according to the context. It is obviously a verbal idiom. In its translation, the literary translator chose the second strategy - using a Hungarian expression of similar meaning but dissimilar form: nem vette fel a kesztyút (Martin 2014). Other acceptable translation possibilities would be the following: nem kapta be a csalit; nem harapott a csalira.

2. Source text: "Will had known they would drag him into the quarrel sooner or later. He wished it had been later rather than sooner" (Martin 2011). The meaning of the idiom to drag (someone) into (something) given in The Free Dictionary - Idioms is the following: to force, impel, involve, or convince someone to participate in an undesirable situation or action. This is a semi-transparent 
idiom because there are some semantic relations between the meaning of certain constituents and the idiom's meaning. It can be considered changeable both from lexical and grammatical point of view (e.g. the tense of the verb drag can be changed and two words in the structure are changeable - dragged the man into a fight). Regarding its construction, it is a verbal expression. In this case, Pétersz chose the first strategy when translating it into Hungarian - using an expression of approximately similar meaning and similar form: ót (is) belerángatják a vitába (Martin 2014). Some examples for other acceptable translation possibilities can be the following: ót is belesodorják a vitába; ô is belekeveredik a veszekedésbe/a vitába; vitába fog keveredni.

3. Source text: "Gared had spent forty years in the Night's Watch, man and boy, and he was not accustomed to being made light of" (Martin 2011). The meaning of the idiom to make light of given in The Free Dictionary - Idioms is the following: to treat something as if it were unimportant or humorous. This is again an opaque idiom because there is no semantic relation between the meaning of the idiom's constituents and the idiom's meaning. It is changeable from grammatical point of view (the tense and voice of the verb make can be changed according to the context). It is a verbal idiom. Here Pétersz used the third strategy, he paraphrased the idiom: gúnyolódjanak rajta (Martin 2014). Other acceptable translation possibilities would be the following: csúfot üzzenek belóle, kigúnyolják, ne vegyék komolyan.

4. Source text: "Jon saw only a fat man, red-faced under his beard, sweating through his silks. He walked like a man half in his cups." (Martin, 2011). The meaning of the idiom 'in one's cups' given in UsingEnglish.com is the following: if someone is in their cups, they are drunk; or, according to another definition in the Wiktionary: drunk; in the act of consuming alcohol liberally. This can be considered a semi-transparent idiom because some semantic relations can be observed between the meaning of the word cup and the idiom's meaning (drunk) based on the assumption that people often consume alcohol from cups. It is changeable from grammatical point of view (the possessive adjective his can be changed). It is a verbless idiom. In the Hungarian translation, Pétersz used the third strategy, he paraphrased the idiom: félig máris kapatos (Martin, 2014). Other acceptable translation possibilities would be the following: félig részeg, becsípett, félrészeg.

5. Source text: "She heard a shout, saw a shove, and in the blink of an eye the arakhs were out, long razor-sharp blades, half sword and half scythe. A dance of death began as the warriors circled and slashed, leaping toward each other..." (Martin 2011). The meaning of the idiom in the blink of an eye given in The 
Free Dictionary - Idioms is the following: extremely quickly. This is an opaque idiom because there is no semantic relation between the meaning of the idiom's constituents and the idiom's meaning. From the point of view of its fixedness, it is unchangeable and regarding its construction it is verbless. In the Hungarian translation, Pétersz used the first strategy because in Hungarian there is an idiom of approximately similar meaning and form: egy szempillantás alatt (Martin 2014). Other acceptable translations would be the following: villámgyorsan, egy pillanat alatt.

The analysis gave us the opportunity to find various examples for the previously described idiom typology and some of the different strategies commonly used in the translation of idioms.

Regarding the most frequently chosen strategy by the literary translator was translation by paraphrase. This confirms Baker's opinion, who also concluded that this is the most commonly used strategy. The strategy of paraphrasing was followed in frequency by the attempt of using an idiom of similar meaning but dissimilar form. Pétersz used translation by paraphrase in $55 \%$, an idiom of similar meaning but dissimilar form in $30 \%$, and an idiom of approximately similar meaning and form in $15 \%$. However, we could not find any examples for omission or compensation.

More idioms could have been analysed, but at this point our purpose was not to gather a large number of idiomatic expressions or produce different statistics, but to decide whether certain extracts from the novel can or cannot be used in the teaching process in order to exemplify idiom typology and translation strategies or to be source materials for different vocabulary and translation exercises. Based on our analysis, we believe that the novel may be an appropriate source material for teaching purposes and translation practice in translator training.

\section{Conclusions}

In this study, the purpose of the thorough overview of certain issues regarding the definition, typology, and classification of idioms was to identify the possible causes why idioms are difficult to recognize, understand, and learn. Some relevant factors which might determine the appropriateness and acceptability of their translation and some of the translation strategies recommended in the specialized literature were also presented.

We analysed thirty idioms from the novel "A Game of Thrones" from the point of view of the different typologies found in the specialized literature regarding their semantic characteristics, their fixedness, and constitution. The various idiomtranslating solutions and strategies chosen by the literary translator while translating 
the novel into Hungarian were also examined. As a result of this analysis, we can state that the novel is an eligible source for authentic teaching material.

Based on our results, we believe that different aspects and difficulties of idiom translation can be demonstrated and practised with the help of different tasks based on the original text and its Hungarian translation. The various purposes of these tasks could be the following: to clarify what we mean by the term idiom, get acquainted with the different types of idioms, recognize the different types, recognize the various strategies used in idiom-translation, try to deduce the meaning of idioms from the context, practise idiom-translation with idioms given in context, and try alternative translations of the same idiom within the same context.

In this study, we presented the analysis of only one potential teaching material source, but we believe that other text types - rich in idioms and belonging to different registers, genres, and styles - should also be analysed and used in the teaching process. Therefore, we are going to extend our research in order to be able to use various texts in teaching idiom translation.

Task design and our experience regarding the utilization of this text in translator training will be a topic of a further study.

\section{References}

Baker, M. 1992. In other words: a coursebook on translation. London and New York: Routledge.

Bárdos, J. 2000. Az idegen nyelvek tanításának elméleti alapjai és gyakorlata. Budapest: Nemzeti Tankönyvkiadó.

Brenner, G. 2003. Webster's new world American idioms handbook. Indianapolis: Wiley Publishing, Inc.

Cacciari, C.-Glucksberg, S. 1991. Understanding idiomatic expressions: the contribution of word meanings. In: Simpson, G. B. (ed.), Understanding word and sentence. North-Holland: Elsevier Science Publishers.

Cacciari, C.-Tabossi P. 1993. Idioms: processing, structure, and interpretation. Lawrence Erlbaum Associates, Inc.

Davies, M. G. 2004. Multiple voices in the translation classroom: activities, tasks and projects. Amesterdam and Philadelphia: John Benjamins.

Glucksberg, S. 2001. Understanding figurative language: from metaphor to idioms. Oxford University Press.

Hervey, S.-Higgins I. 2002 [1992]. Thinking French translation. London and New York: Routledge.

Irujo, S. 1986. A piece of cake: learning and teaching idioms. ELT Journal 40(3 July). Oxford University Press. 
Klaudy, K. 2003 [1994]. Languages in translation. Budapest: Scholastica.

Kövecses, Z. 2010. Metaphor: a practical introduction. Oxford: Oxford University Press.

Kvetko, P. 2009. English lexicology in theory and practice. Trnava.

Martin, George R. R. 2011 [1996]. A Game of thrones. London: Harper Voyager. 2014. Trónok harca. Budapest: Alexandra Kiadó.

McPherron, P.-Randolph, P. T. 2014. Cat got your tongue?: Recent research and classroom practices for teaching idioms to English learners around the world. TESOL Press.

Newmark, P. 1988. A textbook on translation. New York, London: Prentice Hall.

Reiss, K. 2014 [2000]. Translation criticism - potentials and limitations. London and New York: Routledge.

Richards, J. C.-Schmidt R. 2010 [1985]. Longman dictionary of language teaching and applied linguistics. London: Pearson.

Seidl, J.-Mc Mordie, W. 1988 [1978]. English idioms (5 ${ }^{\text {th }}$ edition). Oxford, New York: Oxford University Press.

\section{Internet sources}

Cacciari, C. 1993. The place of idioms in a literal and metaphorical world. https:// www.researchgate.net/publication/238123412. (30 March 2016).

Pilkington, R. English idioms dictionary. http:/www.slideshare.net/ RalphPilkington/englishidioms. (28 February 2016).

Strakšiene, M. 2009. Analysis of idiom translation strategies from English into Lithuanian. Studies about languages 14: 13-19. http://www.kalbos.lt/ zurnalai/14_numeris/03.pdf. (29 March 2016).

\section{Online dictionaries}

http://idioms.thefreedictionary.com http://www.usingenglish.com/reference/idioms/ https://en.wiktionary.org/wiki/Wiktionary:Main_Page 